\title{
Effect of Reynolds Number and Property Variation on Fluid Flow and Heat Transfer in the Entrance Region of a Turbine Blade Internal-Cooling Channel
}

\author{
R. Ben-Mansour \\ Department of Mechanical Engineering, King Fahd University of Petroleum and Minerals, Dhahran 31261, Saudi Arabia \\ Email: rmansour@kfupm.edu.sa \\ L. Al-Hadhrami \\ Department of Mechanical Engineering, King Fahd University of Petroleum and Minerals, Dhahran 31261, Saudi Arabia \\ Email: luaimalh@kfupm.edu.sa
}

Received 10 December 2003

\begin{abstract}
Internal cooling is one of the effective techniques to cool turbine blades from inside. This internal cooling is achieved by pumping a relatively cold fluid through the internal-cooling channels. These channels are fed through short channels placed at the root of the turbine blade, usually called entrance region channels. The entrance region at the root of the turbine blade usually has a different geometry than the internal-cooling channel of the blade. This study investigates numerically the fluid flow and heat transfer in one-pass smooth isothermally heated channel using the RNG $k-\varepsilon$ model. The effect of Reynolds number on the flow and heat transfer characteristics has been studied for two mass flow rate ratios (1/1 and 1/2) for the same cooling channel. The Reynolds number was varied between 10000 and 50000 . The study has shown that the cooling channel goes through hydrodynamic and thermal development which necessitates a detailed flow and heat transfer study to evaluate the pressure drop and heat transfer rates. For the case of unbalanced mass flow rate ratio, a maximum difference of $8.9 \%$ in the heat transfer rate between the top and bottom surfaces occurs at $\mathrm{Re}=10000$ while the total heat transfer rate from both surfaces is the same for the balanced mass flow rate case. The effect of temperature-dependent property variation showed a small change in the heat transfer rates when all properties were allowed to vary with temperature. However, individual effects can be significant such as the effect of density variation, which resulted in as much as $9.6 \%$ reduction in the heat transfer rate.
\end{abstract}

Keywords and phrases: cooling, blade, entrance, flow, heat, variable properties.

\section{INTRODUCTION}

To increase the gas turbine cycle efficiency, it is necessary to adopt internal air cooling channels to reduce the effects of high-temperature path coming from combustor. Internalcooling channels are extremely complex and Figure 1 illustrates this point for modern rotor blade. These channels are supplied by air through short channels located at the root of the turbine blade called entrance channels. The crosssectional geometry of the entrance channels is usually different than the cross-sectional geometry of the cooling channels. As a result, the coolant air is not thermally and hydrodynamically fully developed. Most of the studies which have been conducted experimentally or numerically neglected this

This is an open access article distributed under the Creative Commons Attribution License, which permits unrestricted use, distribution, and reproduction in any medium, provided the original work is properly cited. fact and considered the entrance channels at the root of the turbine blade, and the internal-cooling channels have exactly the same cross-sectional geometry, which is not a true situation in the real design of internal-cooling channels.

Numerous studies have been carried out on turbulent flow and heat transfer in the cooling channels. Han [1] studied the effect of Reynolds number on the centerline heat transfer coefficient of a square channel, two rectangular channels, and two rib spacings. The heat transfer distribution was presented by Nusselt number ratio with several Reynolds numbers, and they showed similar trends except that the Nusselt number ratios decreased slightly with increasing Reynolds numbers.

Han et al. [2] performed a study of the effect of the rib angle on heat transfer distributions and pressure drop in a stationary square channel with two opposite inline ribbed walls. These studies showed that the $60^{\circ}$ and $45^{\circ} \mathrm{V}$-shaped ribs perform better than the $60^{\circ}$ and $45^{\circ}$ parallel ribs. It was 


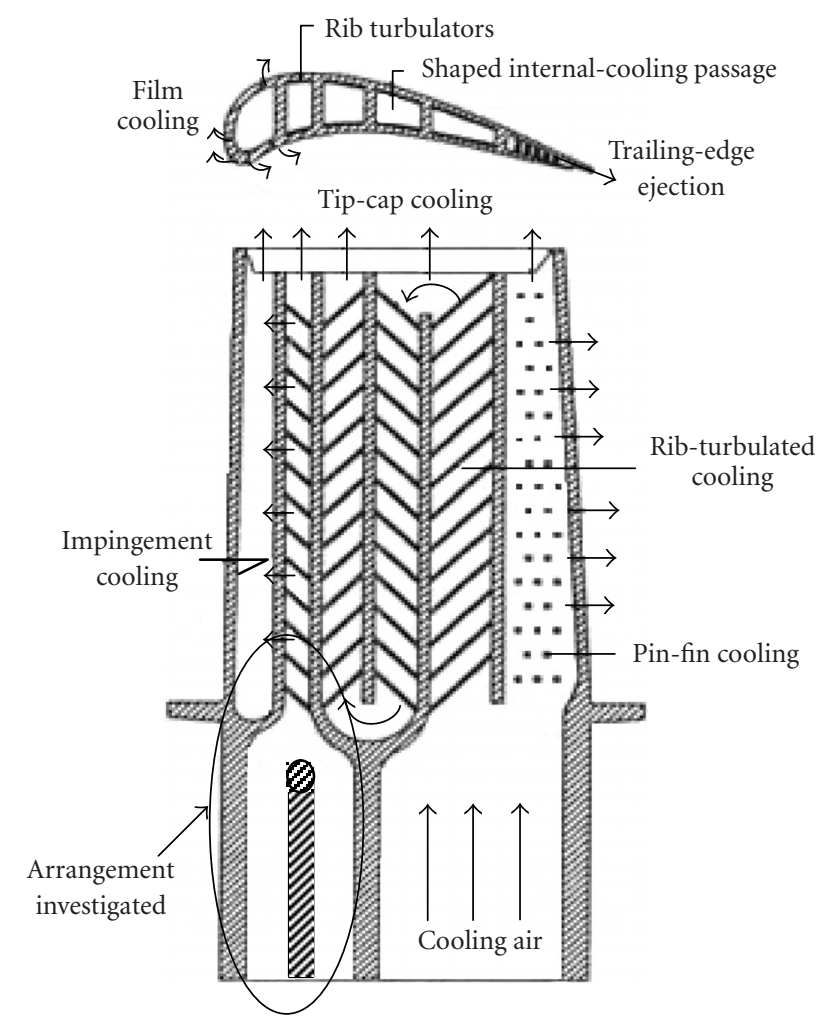

FIgURE 1: Cross-sectional view for the internal-cooling channels of a typical blade turbine.

also concluded that the V-shaped ribs outperform the $60^{\circ}$ and $45^{\circ}$ crossed ribs as well as the $90^{\circ}$ ribs.

Han and Zhang [3] conducted experiments to study the broken parallel V-shaped ribs. The results showed that for all ribs, the Nusselt ratio decreases and friction factor ratio increases with increasing Reynolds number. The results also showed that the ribbed-side Nusselt number ratios for $60^{\circ}$ and $45^{\circ}$ parallel broken ribs or $\mathrm{V}$-shaped broken ribs are much higher than the corresponding $60^{\circ}$ and $45^{\circ}$ parallel continuous ribs or $\mathrm{V}$-shaped continuous ribs.

Han et al. [4] studied the influence of surface heat flux ratio on heat transfer. Different parallel, crossed, and Vshaped ribs were used. Six different wall heat flux ratios were studied. The results showed that the effect of wall heat flux on the heat transfer performance decreases with increasing Reynolds numbers. The heat transfer performance of $60^{\circ} \mathrm{V}$ shaped ribs is higher than the $60^{\circ}$ parallel ribs, $60^{\circ}$ crossed ribs, and $90^{\circ}$ ribs, regardless of the wall heat flux ratio.

Park et al. [5] studied the heat transfer distribution and pressure drop in five straight rectangular channels of different aspect ratios. The results showed that for $60^{\circ}$ ribs, the heat transfer augmentations do not vary significantly, but the pressure drop penalties increase dramatically from 2 to 8 folds when the channel aspect ratio changes from narrow to wide (1/4 to 4$)$. Similar results are observed for $45^{\circ}$ and $90^{\circ}$ ribs.

Taslim and Lengkong [6] studied the heat transfer coefficient in a channel with high blockage staggered rib spacing of 5 rib heights showing the highest heat transfer coefficient distribution in the group. Taslim and Lengkong [7] studied the staggered $45^{\circ}$ ribs with smaller blockage ratio. The results revealed that the heat transfer coefficients are higher than $90^{\circ}$ ribs of similar arrangement.

Chandra and Cook [8] studied the effects of the number of ribbed walls on heat transfer and friction characteristics in a square channel. The results showed that the heat transfer coefficient and the pressure drop increase with an increase in the number of ribbed walls. This increase in the heat transfer coefficient is noted in both the smooth and ribbed walls. The smooth wall shows an increase of about $13 \%$ in heat transfer coefficient for additional ribbed surface, whereas the ribbed surface showed about $10 \%$ increase in the heat transfer coefficient with additional ribbed surface.

Chandra et al. [9] studied the effect of ribbed walls on a rectangular channel. Similar to their square channel configuration, they varied the number of ribbed walls. They noticed that the ribbed-side heat transfer shows a better performance when only one of the wider sides is rib roughened compared to when both short sides are rib roughened. Also, they presented the $G$ and $R$ correlation for these partially ribbed channels.

Taslim et al. [10] measured heat transfer coefficient and friction factors in partially ribbed channels. A liquid-crystal technique was used, and channel cross-sections were selected to represent the mid-chord section of an airfoil. The results showed that the addition of partial ribs significantly improved the heat transfer from the major heat transfer surfaces. Addition of partial ribs increased average wall heat transfer coefficients by about $40 \%$.

Kukreja et al. [11] published detailed measurements in the inter-rib region of adjacent ribs to analyze the process of separation and reattachment in detail. They used naphthalene sublimation technique and used both $90^{\circ}$ transverse ribs and parallel V-shaped continuous ribs. The reattachment of flow past ribs was clearly identified by this work.

Acharya et al. [12] reported detailed measurement of velocity, temperature, and heat transfer in both ribs placed at a $45^{\circ}$ angle for different rib spacing. The results showed the effect of developed and periodically developed regions of a ribbed channel.

Abuaf and Kercher [13] studied heat transfer and turbulence in turbulent cooling detailed heat transfer coefficients. They used a model built with Plexiglas magnified 10 times to measure the detailed heat transfer coefficients by using liquid-crystal technique. Averaged axial turbulence intensities were also measured with a hot-wire anemometer.

Rau et al. [14] presented detailed heat transfer coefficients in the inter-rib region and smooth sidewalls. The results showed that the heat transfer enhancement for the two ribbed sides is higher than that for the single ribbed side. The flow is symmetric in the two-rib configuration.

All the above-mentioned studies treated the entrance channel at the root of the turbine blade as a straight channel with the same cross-sectional geometry as the internalcooling channel to make the flow entering the cooling channel hydrodynamically fully developed. However, the typical 


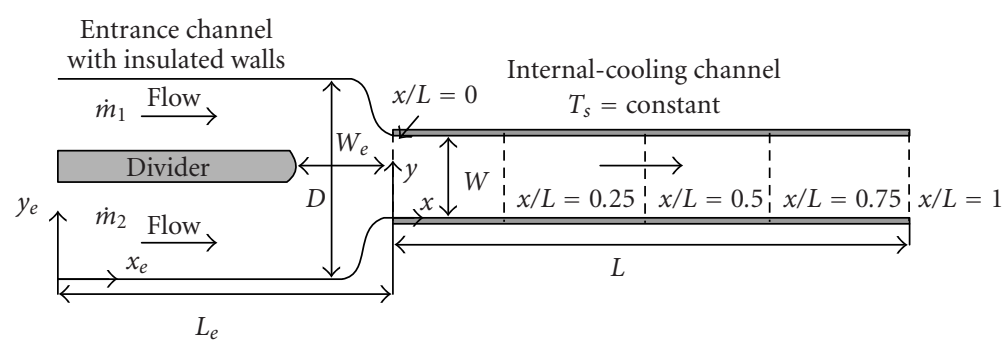

FIgURe 2: Physical model of the cooling channel considered with geometric and flow parameters indicated.

entrance cross-sectional geometry of the channel at the root of the turbine blade has a different cross-sectional geometry than that of the internal-cooling channel. This may cause complex flow behavior. Therefore, it is essential to model realistically the entrance area in order to correctly predict the temperature field and help avoid steep temperature gradients in the skin of the turbine blade, which initiates thermal stresses and shortens the turbine blade life.

The objective of this paper is to study the effect of changing the Reynolds number on the fluid flow and heat transfer in a one-pass, smooth, and isothermally heated channel that is fed through a two-short-channel entrance of different cross-sectional geometry. This type of problem arises not only in turbomachinery applications but also in other applications such as electronic cooling as well as air-conditioning applications. The main part of the study addresses the effect of changing the Reynolds number on the fluid flow and heat transfer inside the cooling channel. At the end of paper, the effect of property variations with temperature is also considered.

\section{PROBLEM FORMULATION AND MODEL}

When looking into many turbine blade designs that are available in the open literature, a common design feature prevails. As shown in Figure 2, a wide entrance channel at the root of the blade is divided into two passages by a short divider to allow the coming flow from both passages to mix before entering into the cooling channel. The length and thickness of this divider vary according to turbine blade design. The anticipation from this design is to strengthen the blade structure and streamline the flow.

The important geometrical parameters of the cooling channel (see Figure 2) include the length of the entrance region $L_{e}$, the width of the entrance region $W_{e}$, the mixing area length $D$, the heated channel length $L$, and the width of the heated channel $W$. Based on typical medium-size turbine blades, the values given to these parameters in this study are $L_{e}=9.5 \mathrm{~cm}, W_{e}=4 \mathrm{~cm}, 1.1 \mathrm{~cm} \leq D \leq 3.1 \mathrm{~cm}, L=10 \mathrm{~cm}$, and $W=1 \mathrm{~cm}$. These are kept unchanged in this study.

The important operating parameters include the mass flow rate per channel depth in upper passage (leg) $\dot{m}_{1}$, the mass flow rate per channel depth in lower passage (leg) $\dot{m}_{2}$, their ratio $\dot{m}_{r}$, the heated surface temperature $T_{s}$, the inlet fluid temperature $T_{\text {in }}$, and the thermophysical properties of the cooling fluid. The parameters give rise to the Reynolds number Re (expressed in terms of the total mass flow rate $\left.\dot{m}_{1}+\dot{m}_{1}\right)$ and a Prandtl number Pr.

This paper presents the effect of changing the Reynolds number on the flow and heat transfer characteristics inside an isothermally heated channel. Although in reality turbine blade cooling channels are neither heated isothermally nor with a constant heat flux, this assumption follows most of the published numerical work to facilitate a systematic analysis of the problem.

CFD computations have been undertaken to solve the incompressible, two-dimensional Navier-Stokes equations with an RNG $k-\varepsilon$ turbulence model for a practical range of Reynolds number. The time-averaged mass, momentum, and energy conservation equations can be written in vector form (2000) as follows.

(i) Continuity:

$$
\nabla \cdot(\rho \bar{V})=0
$$

(ii) Momentum:

$$
\nabla \cdot\left(\rho v_{i} \bar{V}\right)=-\frac{\partial p}{\partial X_{i}}+\nabla \cdot\left(\mu_{\mathrm{eff}} \nabla v_{i}\right)+F_{i}
$$

(iii) Energy:

$$
\nabla \cdot(\rho T \bar{V})=\nabla \cdot\left(\alpha_{\mathrm{eff}} \nabla T\right)+S_{h}
$$

where $\bar{V}$ is the time-averaged velocity vector, $v_{i}$ represents the velocity component in the $i$ th direction, and $F_{i}$ represents the source term for the momentum transport equation in the $i$ th direction. The effective viscosity $\mu_{\text {eff }}$ includes the molecular viscosity $\mu$ and the turbulent eddy viscosity $\mu_{t}$, hence $\mu_{\text {eff }}=$ $\mu+\mu_{t} . S_{h}$ is the source term for the energy equation, and the effective diffusion coefficient is given by $\alpha_{\text {eff }}=(\mu / \operatorname{Pr})+$ $\left(\mu_{t} / \operatorname{Pr}_{t}\right)$, where $\operatorname{Pr}=0.7$ and $\operatorname{Pr}_{t}=0.85$ are the molecular and turbulent Prandtl numbers, respectively.

The solution of the two-dimensional, steady-flow, and energy equations (1), (2), and (3) defined above is obtained by prescribing the following boundary conditions. At all the walls, the no-slip boundary condition is taken $\left(v_{i}=0, i=\right.$ $1,2)$. At the inlet of the entrance region $\left(x=-L_{e}\right)$, a uniform velocity profile is assumed for both legs. At the exit 
TABLE 1: Parametric case labels for different Reynolds numbers and mass flow rate ratios.

\begin{tabular}{ccc}
\hline Case & $\mathrm{Re}$ & $\dot{m}_{r}$ \\
\hline 10 & 10000 & $1 / 1$ \\
11 & 20000 & $1 / 1$ \\
4 & 25000 & $1 / 1$ \\
12 & 30000 & $1 / 1$ \\
13 & 40000 & $1 / 1$ \\
14 & 50000 & $1 / 1$ \\
15 & 10000 & $1 / 2$ \\
16 & 20000 & $1 / 2$ \\
5 & 25000 & $1 / 2$ \\
17 & 30000 & $1 / 2$ \\
18 & 40000 & $1 / 2$ \\
19 & 50000 & $1 / 2$ \\
\hline
\end{tabular}

of the channel $(x=L)$, the flow is assumed to be fully developed. This was later verified to be an acceptable assumption. The active part of the channel is heated isothermally at a temperature $T_{s}$ (for $0 \leq x \leq L, y=0$ and $y=W$, and $\left.T=T_{s}\right)$. The upper and lower walls of the entrance part of the channel as well as the dividing wall are considered insulated $(\partial T / \partial n=0)$. This assumption is taken because our main focus is on the active part of the cooling channel. It may be further argued that the heat transfer rates at the root of the blade (entrance region) are much smaller that the heat transfer rates in the active part of the cooling channel.

The RNG $k-\varepsilon$ turbulence model was used in this study (Choudhury [15]). This model is derived using the renormalized group theory and is based on the standard $k-\varepsilon$ model resulting in fewer turbulence parameter constants. It has shown better accuracy and more agreement with experimental results especially flows with recirculation zones.

In the first part of the study, it is assumed that all thermophysical properties are constants. Because of the relatively large temperature difference, it is expected that these properties will vary with temperature. To check the validity of the above assumption, we allow the properties to vary with temperature in the second part of the study.

\section{RESULTS AND DISCUSSION}

\subsection{Effect of Reynolds number (Re) variation}

In order to evaluate the heat transfer characteristics in the cooling channel immediately after the entry region, two cases were chosen based on a previous study done by the authors (Al-Hadhrami and Ben-Mansour [16]). The first case has a mass flow rate ratio of $1 / 1\left(\dot{m}_{r}=1 / 1\right)$ and mixing length ratio of $L_{r}=1.1$. This case has been shown to have the highest heat transfer among the cases analyzed. The case is referred to as case 4 in Table 1 . The second base case, referred to as case 5 in Table 1 , has $L_{r}=1.1$ but $\dot{m}_{r}=1 / 2$. For both cases 4 and 5, the Reynolds number was varied form 10000 to 50000 resulting in a total of 12 cases as tabulated in Table 1. This range of Re is chosen based on practical turbomachinery applications.

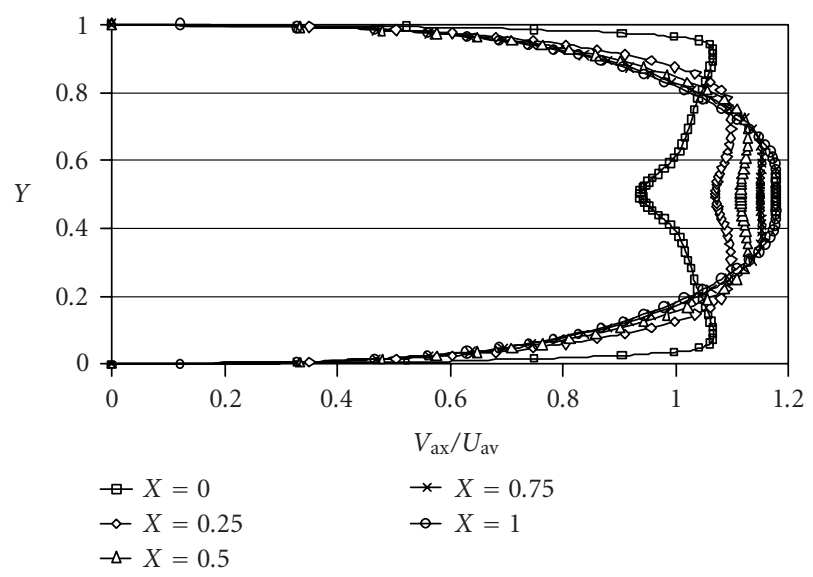

Figure 3: Axial velocity profiles at different sections of the cooling channel for $\operatorname{Re}=10000$ and $\dot{m}_{r}=1 / 1$.

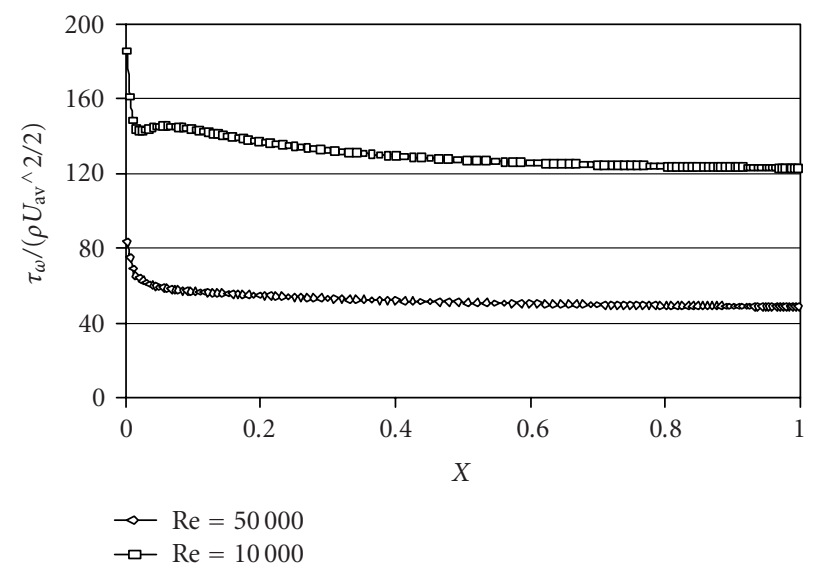

FIGURE 4: Wall shear stress distribution along the channel wall for $\dot{m}_{r}=1 / 1$ and $\operatorname{Re}=10000$ and 50000 .

\subsection{Balanced mass ratio entry: $\dot{m}_{r}=1 / 1$}

The hydrodynamic development in the cooling channel is shown in Figure 3. The axial velocity profiles show that the flow is in a developing stage. The same conclusion can be derived from the wall shear stress depicted in Figure 4. For the high Re value of 50000 , the axial velocity profiles are shown in Figure 5 and the wall shear stress distribution is given in Figure 4. Again at $\mathrm{Re}=50000$, the flow is in development over the entire length of the cooling channel. For generality, all results are shown in nondimensional form where $X=x / L$, and $Y=y / W$ are the nondimensional streamwise and spanwise coordinates, respectively.

Comparing the velocity profiles for cases 10 and 14 having $\mathrm{Re}=10^{4}$ and $5 \times 10^{4}$, respectively, it is noted that in both cases the velocity at the inlet is mainly flat except in the centerline where there is a dip due the stagnation region created by the divider. This dip is more pronounced for the lower Re. As the flow proceeds in the channel, the profile becomes flatter. However, for the low Re of $10^{4}$, the exit profile is almost 


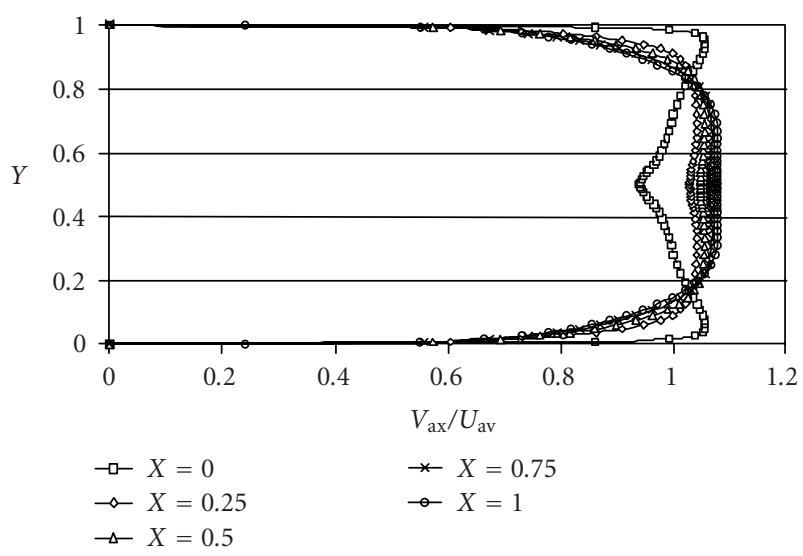

Figure 5: Axial velocity profiles at different sections of the cooling channel for $\operatorname{Re}=50000$ and $\dot{m}_{r}=1 / 1$.

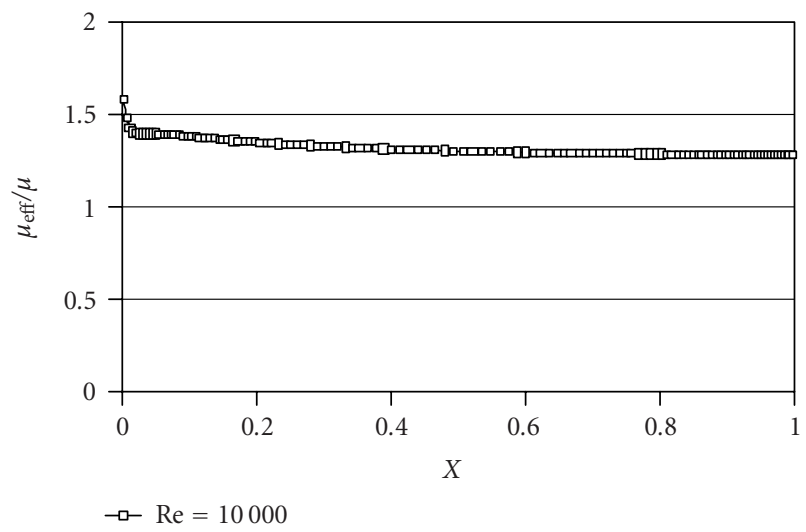

Figure 6: Effective viscosity ratio along the channel wall for $\dot{m}_{r}=$ $1 / 1$ and $\operatorname{Re}=10000$.

parabolic with only $10 \%$ flat profile around the centerline. For $\operatorname{Re}=5 \times 10^{4}$, the exit profile is flat for almost $35 \%$.

In terms of shear stress, it is noted that case 10 has a local maximum at $x=0.1$. This can be either due to the velocity gradients or the effective viscosity. It turns out that the effective viscosity is the main cause as seen in Figure 6. For this case, the effective viscosity has also a local maximum due to relatively high turbulent mixing at that location. The trend disappears for higher Reynolds numbers.

The temperature profiles at the same sections are shown in Figures 7 and 8 for cases 10 and 14, respectively. When comparing both figures, it is noted that the thermal development is slower for the lower Re. Furthermore, the thermal development is still occurring for both cases. The nondimensional heat flux at the bottom (or top) wall for both cases is depicted in Figure 9. The heat flux profiles are highly indicative of a developing thermal boundary layer. Since these fluxes have been nondimensionalized with respect to the maximum enthalpy rate, then a smaller capacity rate results in higher specific heat flux.

Hence, for cases 10 through 14, the velocity and temperature profiles show that the flow is both hydrodynamically

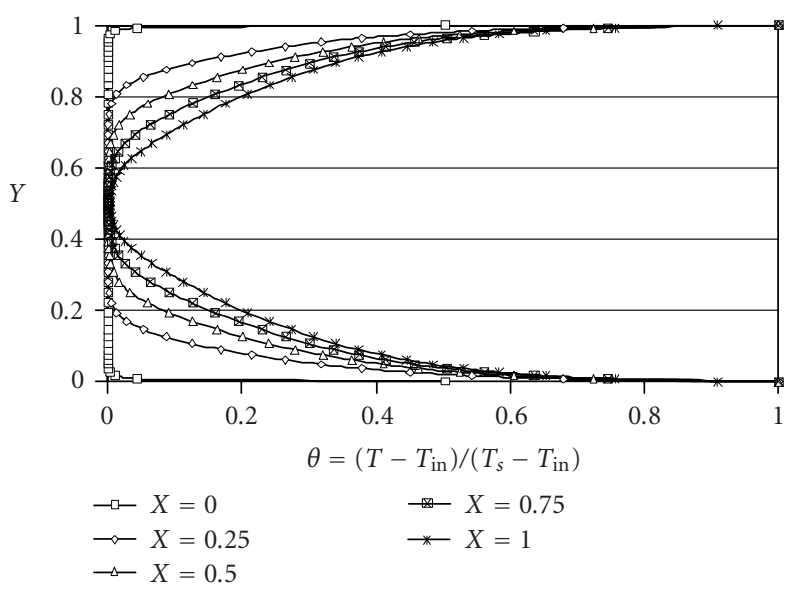

Figure 7: Nondimensional temperature distribution at different sections of the cooling channel for $\operatorname{Re}=10000$ and $\dot{m}_{r}=1 / 1$.

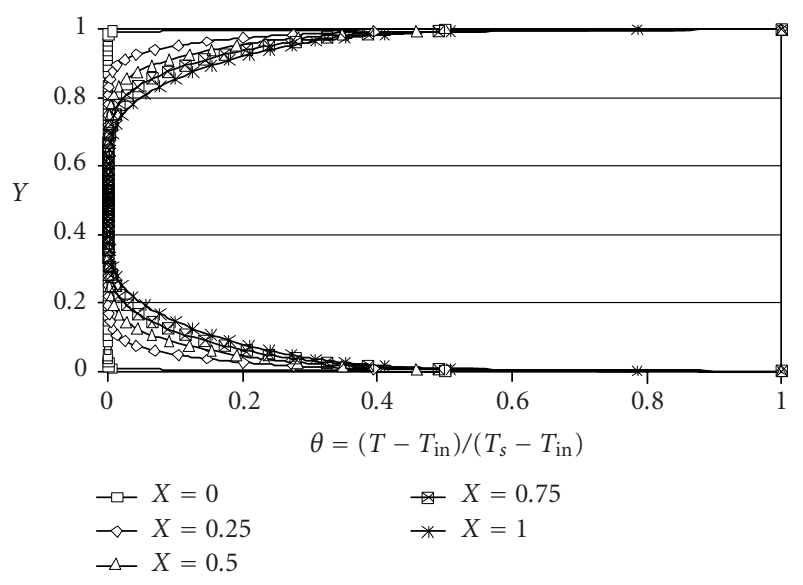

Figure 8: Nondimensional temperature distribution at different sections of the cooling channel for $\operatorname{Re}=50000$ and $\dot{m}_{r}=1 / 1$.

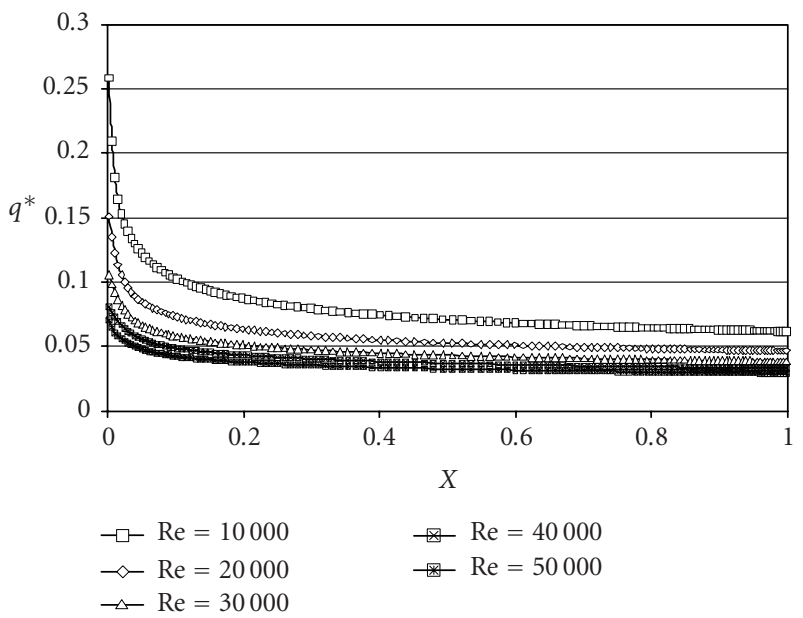

Figure 9: Nondimensional heat flux distribution along the bottom wall of the cooling channel for $\dot{m}_{r}=1 / 1$ and different Reynolds numbers. 


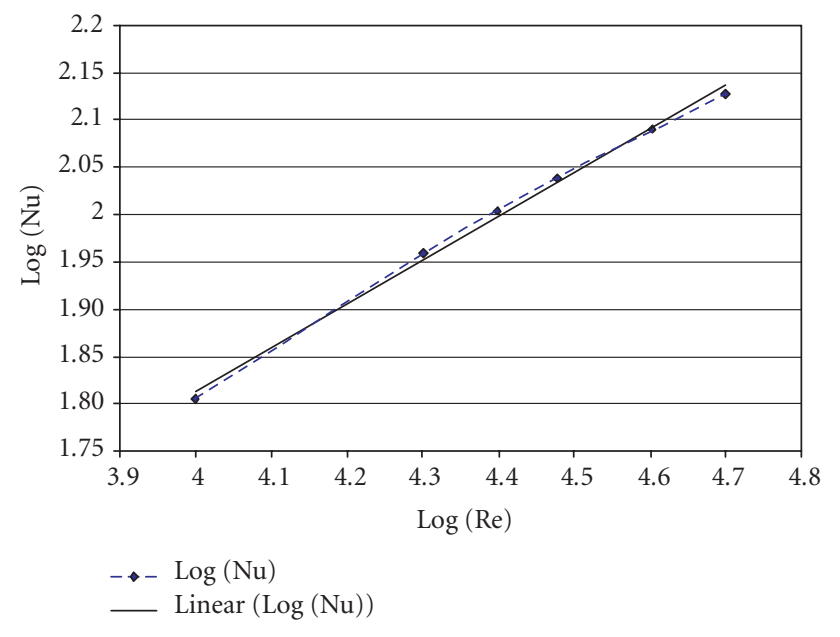

FIGURE 10: Variation of average Nusselt number with Reynolds number for a cooling channel at constant wall temperature and mass flow ratio $\dot{m}_{r}=1 / 1 .\left(y=0.4616 \times-0.0331, R^{2}=0.9959\right.$, $\mathrm{Nu}=0.92662 * \mathrm{Re}^{0.4616}$, or $\mathrm{Nu}=1.04 * \mathrm{Re}^{0.4616^{*}} \operatorname{Pr}^{1 / 3}$.)

and thermally developing in the cooling channel. This development is faster for higher Reynolds number. Since the model is only two dimensional, these conclusions may apply for a cooling channel with low aspect ratio. For channels with an aspect ratio closer to unity, a three-dimensional model is needed to evaluate the flow development.

The heat transfer rate can be expressed in terms of the Nusselt number in order to generalize the results. The average Nusselt number $\mathrm{Nu}$ over the entire channel has been obtained using an LMTD analysis as follows:

$$
\mathrm{Nu}=\frac{h W}{k}=\frac{q W}{2 L \cdot \mathrm{LMTD} \cdot k},
$$

where

$$
\operatorname{LMTD}=\frac{\Delta T_{\text {in }}-\Delta T_{\text {out }}}{\ln \left(\Delta T_{\text {in }} / \Delta T_{\text {out }}\right)}
$$

with $\Delta T=T_{s}-T$. This method is justified because the channel is maintained at a constant surface temperature. The variation of Nusselt number variation with Reynolds number is shown in Figure 10. The data have been fitted with a logarithmic profile as indicated in the figure with a least-square fit of almost 99.7\%. Assuming a dependency on $\operatorname{Pr}^{1 / 3}$ (which should be checked by studying the effect of Pr number), we get the following correlation for the average Nusselt number:

$$
\mathrm{Nu}=1.04^{*} \operatorname{Re}^{0.4616} \operatorname{Pr}^{1 / 3} .
$$

\subsection{Unbalanced mass ratio entry: $\dot{m}_{r}=1 / 2$}

In the following set of cases (15 to 19), the mass flow ratio is $\dot{m}_{r}=1 / 2$ where the mass flow rate entering the bottom part of the entry is twice as much as the mass flow rate entering

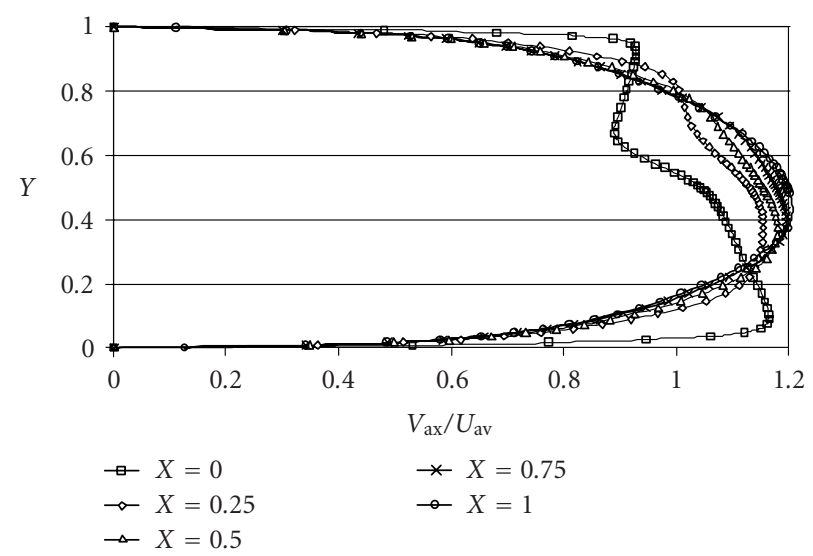

Figure 11: Axial velocity profiles at different sections of the cooling channel for $\operatorname{Re}=10000$ and $\dot{m}_{r}=1 / 2$.

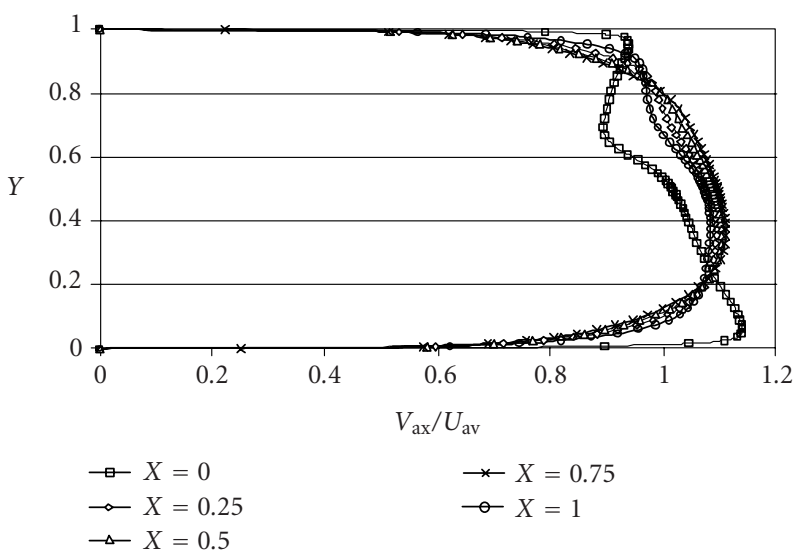

FIgURE 12: Axial velocity profiles at different sections of the cooling channel for $\operatorname{Re}=50000$ and $\dot{m}_{r}=1 / 2$.

the top part. This may be done in a practical way to produce different cooling rates for the top and bottom surfaces of the blade.

At $\mathrm{Re}=10^{4}$, the flow enters the cooling channel with a relatively flat but skewed profile with higher velocity in the bottom part of the channel as plotted in Figure 11. This is mainly due to the larger mass flow rate pumped in the bottom part of the entry. As the flow progresses in the channel, the axial velocity profiles become almost parabolic and skewed towards the bottom. The flow is still developing hydrodynamically. The axial velocity profiles at the same locations for $\mathrm{Re}=5 \times 10^{4}$ are shown in Figure 12. In this case, the flow also enters the cooling channel with a relatively flat but skewed profile. As the flow progresses, it develops into a flat profile for about $35 \%$ of the channel height. The skewness due to the unbalanced mass flow rates is still clear. In both cases, the dip in the velocity profile at the channel inlet, which is produced by the divider, disappears at the outlet section.

The nondimensional temperature profiles at different axial location along the cooling channel for $\mathrm{Re}=10^{4}$ (case 15) 


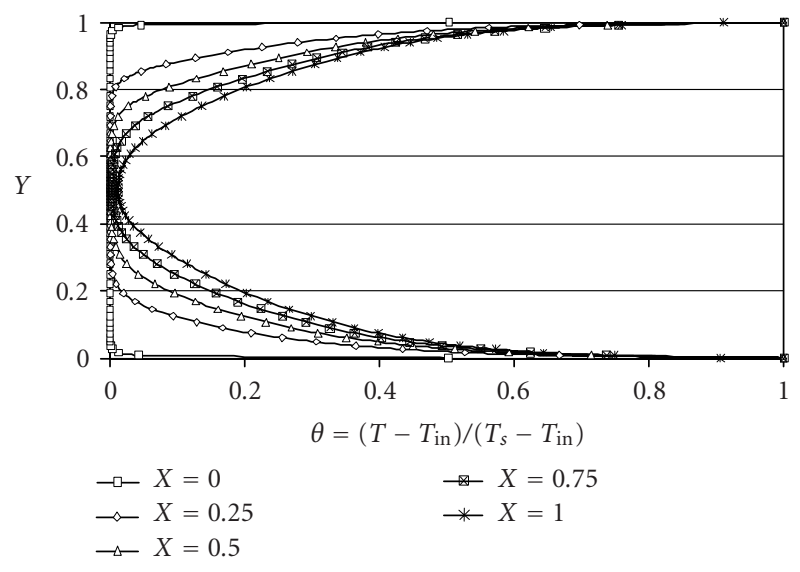

FIgURE 13: Nondimensional temperature distribution at different sections of the cooling channel for $\operatorname{Re}=10000$ and $\dot{m}_{r}=1 / 2$.

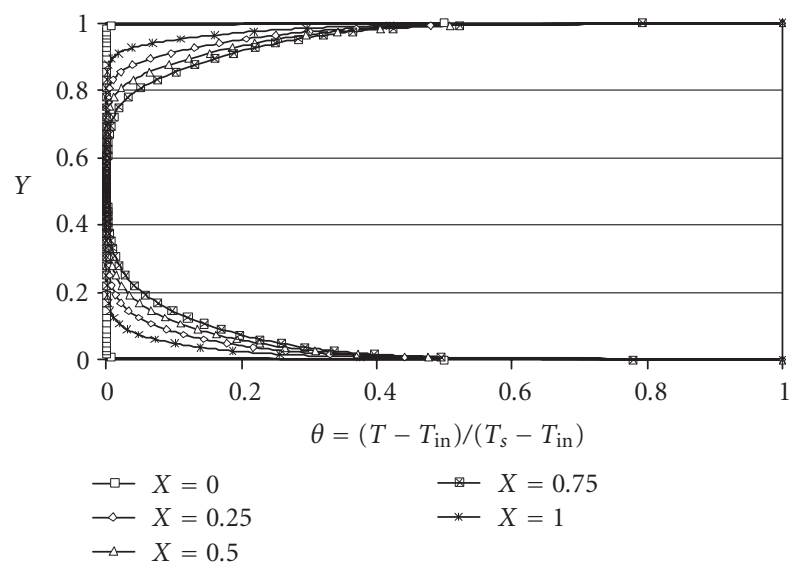

Figure 14: Nondimensional temperature distribution at different sections of the cooling channel for $\operatorname{Re}=50000$ and $\dot{m}_{r}=1 / 2$.

and $\operatorname{Re}=5 \times 10^{4}$ (case 19) are plotted in Figures 13 and 14, respectively. Since the Prandtl number is close to unity $(\operatorname{Pr}=0.71)$, the thermal development in the channel progresses at a similar but relatively slower rate in comparison with the hydrodynamic development. This can be seen as one compares the nondimensional profiles of velocity against the nondimensional profiles of temperature (e.g., Figure 11 versus Figure 13 or Figure 12 versus Figure 14). The imbalance in flow rates produces a difference in the heat flux distribution between the bottom and top wall. A nondimensional heat flux is defined as

$$
q^{*}=\frac{q^{\prime \prime} W L}{\left(\dot{m}_{1}+\dot{m}_{2}\right) c_{p}\left(T_{s}-T_{\mathrm{in}}\right)} .
$$

The distribution of $q^{*}$ along the bottom and top walls of the channel is shown in Figure 15 for cases 15 and 19. It is observed that the difference in heat flux (and the integrated heat rates) between the top and bottom walls diminishes as Re increases. In addition, it is noted that the profiles are flatter for higher Re indicating fuller development as Re increases.

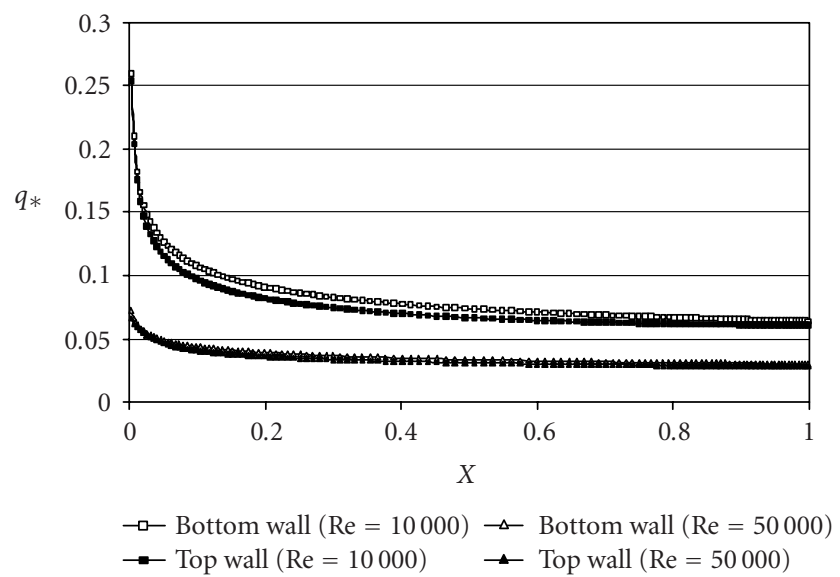

Figure 15: Nondimensional heat flux distribution along the top and bottom walls of the cooling channel for $\dot{m}_{r}=1 / 2$ and $\operatorname{Re}=$ 10000 and 50000 .

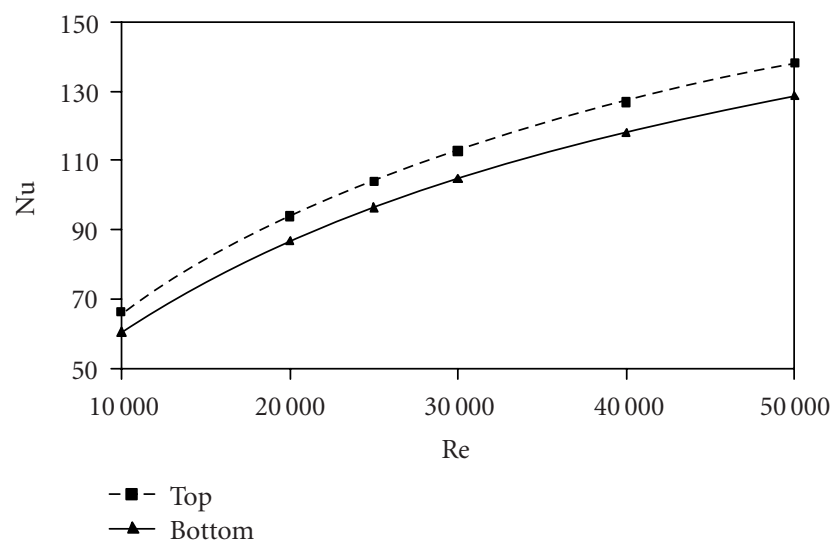

FIGURE 16: Average Nusselt distribution over the top and bottom walls of the cooling channel for $\dot{m}_{r}=1 / 2$ and different Reynolds numbers.

Finally, the average Nusselt number for all the cases simulated has been derived for the top and bottom walls following an LMTD analysis as done for the cases of $\dot{m}_{r}=1 / 1$ above. The resulting values of $\mathrm{Nu}$ are shown in Figure 16. The percent difference between the top and bottom $\mathrm{Nu}$ is calculated and shown in Table 2 . The largest difference of $8.9 \%$ occurs at the lowest $\operatorname{Re}$ of $10^{4}$. The difference then decreases to $7.0 \%$ for $\operatorname{Re}=5 \times 10^{4}$.

\subsection{Effect of property variation with temperature}

The actual temperature range simulated varies between $294 \mathrm{~K}$ (inlet temperature) and $400 \mathrm{~K}$ (surface temperature). In this temperature range, the air density varies approximately $25 \%$, the thermal conductivity varies about $30 \%$, and the dynamic viscosity varies almost $26 \%$. Hence, one should expect that the property variation would affect the flow and heat transfer characteristics. Hence, it would of interest to check the effect of temperature-varying properties. We consider case 4 (see Table 1) as the base case with constant air 
TABLE 2: Average Nusselt numbers over the top and bottom walls of the cooling channel for $\dot{m}_{r}=1 / 2$ and different Reynolds numbers.

\begin{tabular}{ccccc}
\hline Case & Re & Nu-bot & Nu-top & Diff.\% \\
\hline 15 & 10000 & 66.33 & 60.66 & 8.9 \\
16 & 20000 & 94.03 & 87.05 & 7.7 \\
5 & 25000 & 104.10 & 96.61 & 7.5 \\
17 & 30000 & 112.73 & 104.81 & 7.3 \\
18 & 40000 & 126.79 & 118.08 & 7.1 \\
19 & 50000 & 138.12 & 128.73 & 7.0 \\
\hline
\end{tabular}

properties $\left(\rho=1.225 \mathrm{~kg} / \mathrm{m}^{3}, k=0.0242 \mathrm{~W} / \mathrm{m} \cdot \mathrm{K}, \mu=\right.$ $1.7894 \times 10^{-5} \mathrm{~kg} / \mathrm{m} \cdot \mathrm{s}$ taken at a reference value of $T=287 \mathrm{~K}$ ) and we implement the property variation in three stages.

Three tests were simulated to study the effect of each property. In the first test, the effect of density variation with temperature was included by adopting the ideal gas law. To avoid computational difficulties, the effect of pressure variation is neglected. This resulted in a decrease of about $9.6 \%$ in the integrated heat transfer rate. In the second test in addition to adopting the ideal gas law, a piecewise linear fit of thermal conductivity with temperature is used. This resulted in an overall decrease of $3.8 \%$ with respect to the constant property case. In the third test, the effect of dynamic viscosity variation is introduced in the second test. A piecewise linear fit was used. The overall change resulted in a $1.67 \%$ with respect to the constant property case.

It can be concluded that the effect of properties variation with temperature on the heat transfer rate and other flow characteristics is small and hence the assumption of constant properties is valid within the conditions of the study.

\section{CONCLUSIONS}

The effect of Re on the flow and heat transfer characteristics has been studied for two mass flow rate ratios (1/1 and 1/2) for the same cooling channel. The Reynolds number was varied between 10000 and 50000 , and 12 total cases were simulated using a two-dimensional approach with RNG $k-\varepsilon$ turbulence model. The length of the channel $L$ was taken 10 times its width $W$. Although, it may be customary to assume fully developed flow in engineering calculations, this simulation has shown that the cooling channel goes through hydrodynamic and thermal development which necessitates a detailed flow and heat transfer study to evaluate the pressure drop and heat transfer rates. Even though the flow is fully turbulent, it has been shown that the development is a function of Re. This may be due to the two-dimensional nature and need to be verified in a future study. The study has shown that for the unbalanced mass flow rate a maximum difference of $8.9 \%$ in the heat transfer rate between the top and bottom surfaces occurs at $\operatorname{Re}=10000$. This difference drops down to $7 \%$ as Re is increased to 50000 . In addition, the total heat transfer rate from both surfaces is the same for the balanced mass flow rate case.

The effect of property variation with temperature has been incorporated in steps. First, the density ideal gas law has been implemented keeping other properties constant. This change has resulted in $9.6 \%$ decrease in heat transfer in comparison with constant property case. In the second stage, the thermal conductivity is taken as function of temperature resulting in an overall 3.6\% decrease in heat transfer. This means that a temperature-dependent conductivity increases the heat transfer. Finally, a temperature-dependent viscosity is set, resulting in an overall heat transfer decrease of $1.6 \%$. Again this means that a higher viscosity has resulted in an increase of heat transfer through the change of both velocity and temperature profiles.

\section{ACKNOWLEDGMENT}

This work was supported by King Fahd University of Petroleum and Minerals. This support is greatly appreciated.

\section{REFERENCES}

[1] J. C. Han, "Heat transfer and friction characteristics in rectangular channels with rib turbulators," ASME Journal of Heat Transfer, vol. 110, pp. 321-328, 1988.

[2] J. C. Han, Y. M. Zhang, and C. P. Lee, "Augmented heat transfer in square channels with parallel, crossed, and V-shaped angled ribs," ASME J. Heat Transfer, vol. 113, pp. 590-596, 1991.

[3] J. C. Han and Y. M. Zhang, "High performance heat transfer ducts with parallel broken and V-shaped broken ribs," International Journal of Heat and Mass Transfer, vol. 35, no. 2, pp. 513-523, 1992.

[4] J. C. Han, Y. M. Zhang, and C. P. Lee, "Influence of surface heat flux ratio on heat transfer augmentation in square channels with parallel, crossed, and V-shaped angled ribs," ASME J. of Turbomachinery, vol. 114, pp. 872-880, 1992.

[5] J. S. Park, J. C. Han, Y. Huang, and S. Ou, "Heat transfer performance comparisons of five different rectangular channels with parallel angled ribs," International Journal of heat and mass transfer, vol. 35, no. 11, pp. 2891-2903, 1992.

[6] M. E. Taslim and A. Lengkong, "45-degree round-corner rib heat transfer coefficient measurements in a square channel," in 43rd ASME International Gas Turbine \& Aeroengine Congress/User Symposium \& Exposition, Stockholm, Sweden, June 1998, Paper 98 Gt-176.

[7] M. E. Taslim and A. Lengkong, " $45^{\circ}$ staggered rib heat transfer coefficient measurements in a square channel," ASME J. of Turbomachinery, vol. 120, pp. 571-580, 1998.

[8] P. R. Chandra and M. M. Cook, "Effect of the number of channel ribbed walls on the heat transfer and friction characteristics of turbulent flows," in Proc. 6th AlAA/ASME Thermophysics and Heat Transfer Conference in Colorado Springs, vol. 271, pp. 201-209, Colorado, Colo, USA, June 1994.

[9] P. R. Chandra, M. E. Niland, and J. C. Han, "Turbulent flow heat transfer and friction in a rectangular channel with varying number of ribbed walls," ASME J. of Turbomachinery, vol. 119, pp. 374-380, 1997.

[10] M. E. Taslim, T. Li, and S. D. Spring, "Measurements of heat transfer coefficients and friction factors in passages ribroughened on all walls," ASME J. of Turbomachinery, vol. 120, pp. 564-570, 1998.

[11] R. T. Kukreja, S. C. Lau, and R. D. McMillin, "Local heat/mass transfer distribution in a square channel with full and Vshaped ribs," International Journal of Heat and Mass Transfer, vol. 36, no. 8, pp. 2013-2020, 1993. 
[12] S. Acharya, T. Myrum, S. Sinha, and X. Qiu, "Developing and periodically developed flow, temperature and heat transfer in a ribbed duct," Intl. Journal of Heat and Mass Transfer, vol. 40, no. 2, pp. 461-480, 1997.

[13] N. Abuaf and D. M. Kercher, "Heat transfer and turbulence in a turbulated blade cooling circuit," in Proc. 37th International Gas Turbine and Aeroengine Congress and Exposition, Cologne, Germany, June 1992, ASME Paper 92-GT-187.

[14] G. Rau, M. Cakan, D. Moeller, and T. Arts, "The effect of periodic ribs on the local aerodynamic and heat transfer performance of a straight cooling channel," ASME J. of Turbomachinery, vol. 120, pp. 368-375, 1998.

[15] D. Choudhury, "Introduction to the renormalization group method and turbulence modeling," Fluent Inc. Technical Memorandum TM-107, 1993.

[16] L. AL-Hadhrami and R. Ben-Mansour, "Effect of entrance geometry of fluid flow and heat transfer in one pass smooth isothermally heated channel," in Proc. 14th International Symposium of Transport Phenomena, pp. 197-202, Bali, Indonesia, July 2003. 

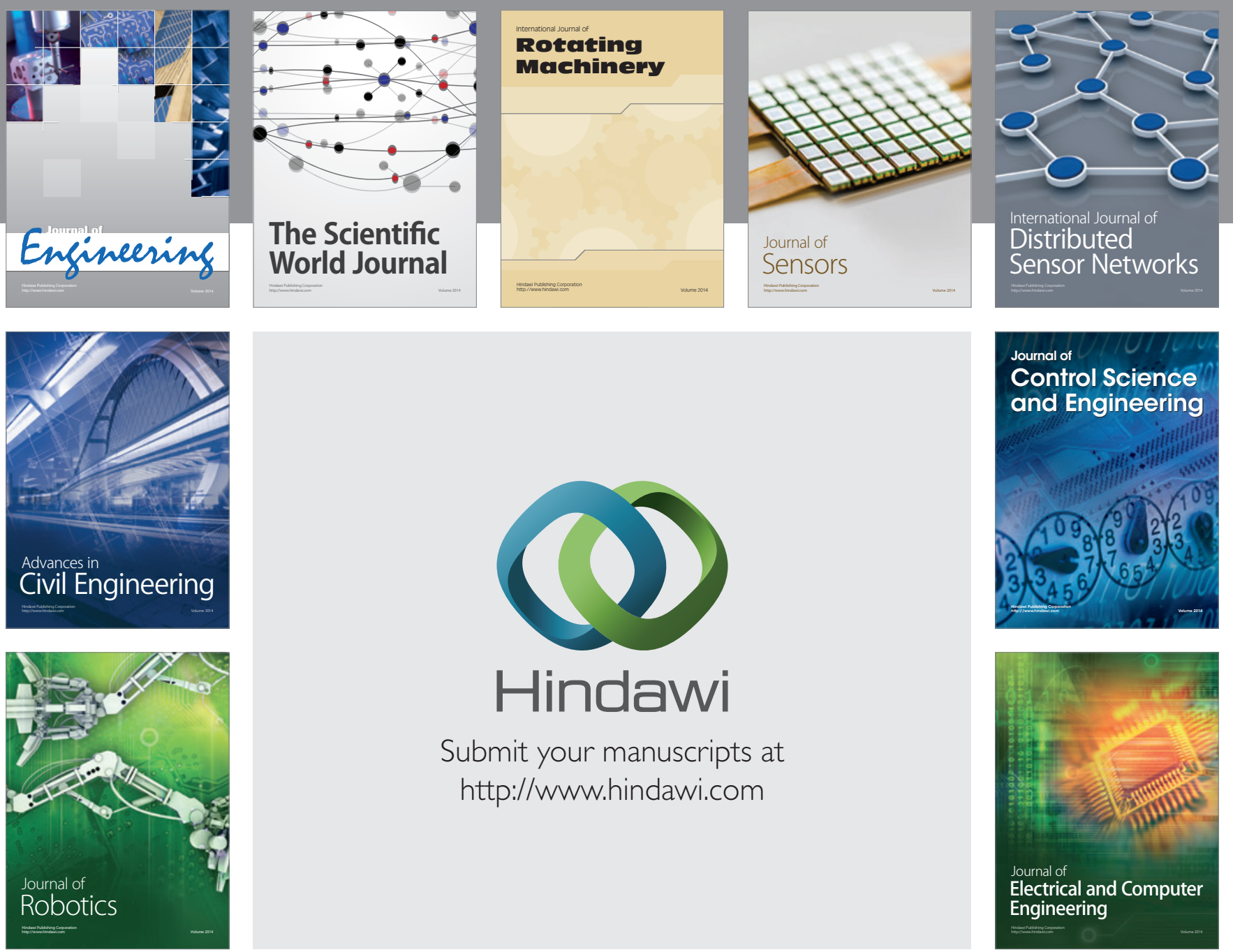

Submit your manuscripts at

http://www.hindawi.com
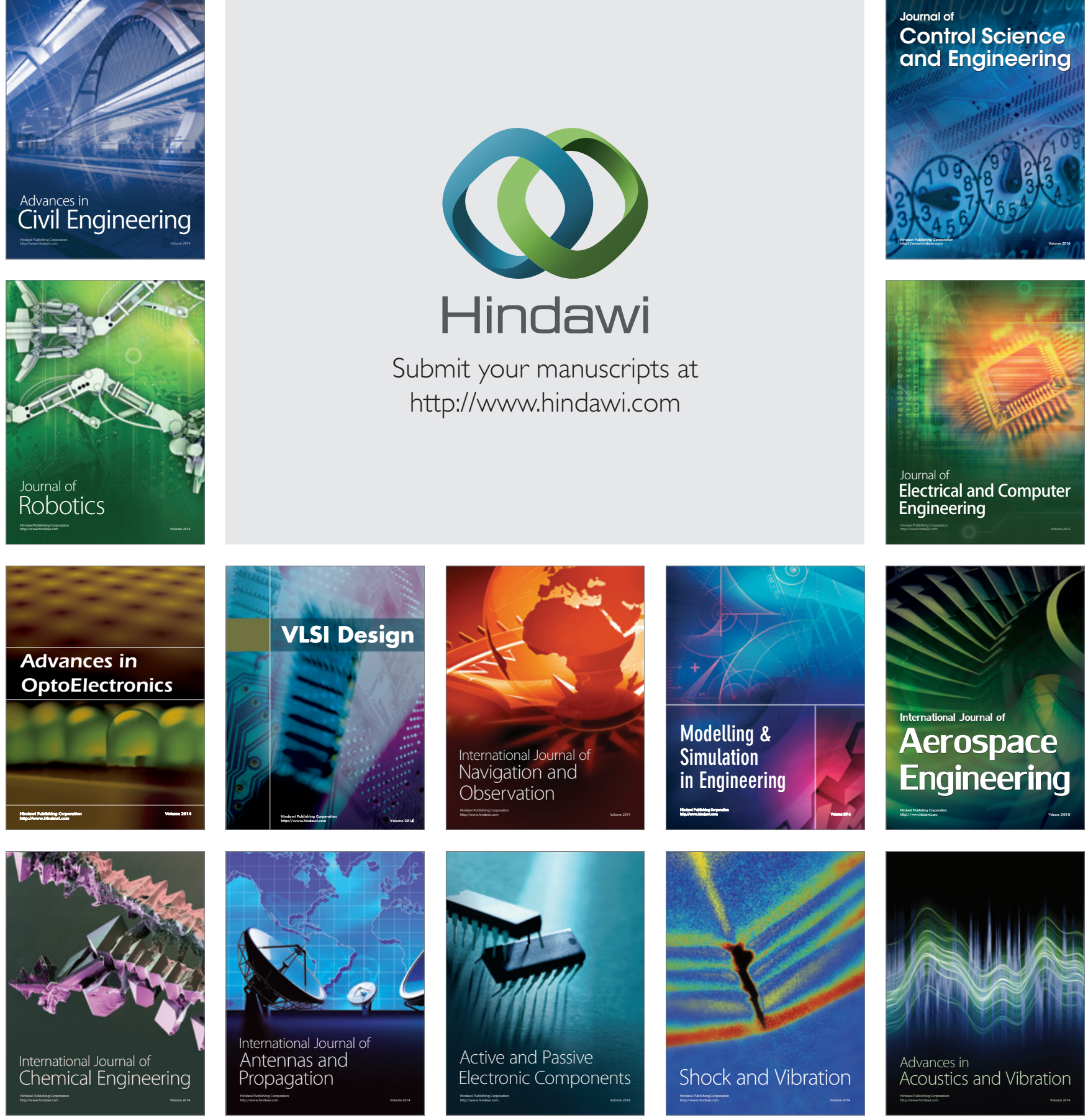